\title{
Five Years Survival Trend and Outcome among HIV Infected Children Followed Up in the Pediatric Department in a Tertiary Hospital
}

Adedemy $\mathrm{JD}^{1^{*}}$, Agbeille $\mathrm{MF}^{1}$, Agossou $\mathrm{J}^{1}$, Noudamadjo $\mathrm{A}^{1}$, Kpanidja $\mathrm{G}^{1}$, Aisso $U^{1}$, Chabi Biaou $\mathrm{A}^{2}$, Lalya HF ${ }^{3}$, Seydou $L^{1}$ and Koumakpaï-Adeothy $S^{4}$

${ }^{1}$ Faculty of Medicine, Department of Mother and Child, University of Parakou, Bénin

${ }^{2}$ Regional Institute of Public Health (IRSP), Ouidah, Bénin

${ }^{3}$ Faculty of Health Sciences, Pediatric Ward, Mother and Child Department, University of Abomey Calavi, Benin

${ }^{4}$ Professeur Honoraire de Pédiatrie, Cotonou, Bénin

*Corresponding author: Dr. Julien Didier ADEDEMY, Faculté de Médecine, Maître de Conférences Agrégé de Pédiatrie, Université de Parakou, Bénin, Tel: (00229)95348555/(00229)97305490,E-mail: kofadier@yahoo.fr

\begin{abstract}
Background: HIV infection still contributes significantly to high leatlity among infant and child. The aim of this work was to assess survival rate after five years of routine follow up among HIV 1-infected children in the pediatric ward of the Parakou Teaching Hospital.

Patients and methods: It was a descriptive cohort study with analytical purpose covering Five years from 2011 to 2016. It focused on 89 HIV 1 -infected children. Kaplan-Meier method was used to estimate the survival probabilities. The survival trends were compared with Log-rank test. Cox regression test was used to identify factors associated with child deaths.

Results: The HIV1-infected children had an average age of 3 years at admission. Most of children were on first line ART and most complications were malnutrition, pneumonia, pulmonary tuberculosis and oral candidosis. The probability of survival at 60 months was 0.7637 . Factors associated with their deaths were the lack of children occupation ( $p=$ $0.039) ; 4^{\text {th }}$ WHO clinical stage $(p<0.001)$ with 39 fold higher risk than children at WHO clinical stage 1 ; poor follow-up ( $p$ $=0.007$ ) with 5.86 times fold higher risk than children with good follow up and malnutrition $(p=0.003)$ with 4.92 times fold higher risk than children with normal $Z$ score.

Conclusion: This result will help clinicians to improve the survival rate of infected children through systematic screening at each contact with the health system, a rapid care of children at birth and regularity in children's follow-up monitoring with therapeutic education.
\end{abstract}

\section{Keywords}

Survival rate, HIV infected children, Follow up, HIV1, Factors associated with death, Benin

\begin{abstract}
Abbreviations
ART: Anti Retroviral Therapy; CTM: Cotrimoxazole; UNAIDS: United Nation Funds for AIDS Disease; PMTCT: Prevention of Mother to Child Transmission; CD4: Lymphocyte CD4 Count; CHUD BA: Parakou Teaching Hospital; HIVIAIDS: Human Immuno Deficience Virus/Acquire Immuno Deficience Syndrome; DNA PCR: DNA Polymerase Chain Reaction; VL: Viral Load; PLC: Programmable Logic Controller; MAM: Moderate Acute Malnutrition; SAM: Severe Acute Malnutrition; AZT: Zidovudine; EFV: Efavirenz; NVP: Nevirapine; 3TC: Lamivudine; TDF: Tenofovir; ABC: Abacavir; LPV/r: Ritonavir Boosted Lopinavir; TB: Tuberculosis
\end{abstract}

\section{Introduction}

With its many economical, cultural and psychosocial consequences, Human Immunodeficiency Virus (HIV) infection remains a heavy burden and a serious development issue for developing countries. Since its first description in the United States in the 1980s [1], according to UNAIDS, HIV/AIDS infection has affected more than 36.7 million people worldwide in 2015, including 2.1 million new cases [2]. The pandemic affects Sub Saharan Africa much more, which accounts for $69 \%$ of the 
world's infected population [3]. According to UNAIDS in 2015 , there were 6.5 million people living with HIV in West and Central Africa, 66,000 new HIV infections occurred in children, while 150,000 new paediatric HIV infections were recorded worldwide during the same period [2].

HIV contributes enormously to child mortality, as approximately $14 \%$ of HIV-related deaths worldwide occur in children [4]. In infected children, the natural course of HIV infection is particularly rapid. In the absence of highly active antiretroviral therapy (HAART), 52\% of HIV-infected children in Africa die before their second birthday [5]. The others have a slower evolution. AIDS stage of the disease is quickly reached around 6 years of age in $40 \%$ of cases [6]. According to a study conducted by Lawson-Evi, et al. in Togo in 2010, the mortality rate of infected children was $50 \%$ during the first two months of life [7]. The medical care of these children, which relies mainly on cotrimoxazole prophylaxis and triple antiretroviral therapy, significantly improves their survival but represents a major public health challenge in Africa [8]. The estimated contribution of adult HIV prevalence to the observed level of under- 5 mortality tended to decrease with the level of HIV prevalence [9]. In Benin, the prevalence of HIV infection is estimated at $1.2 \%$ in $2013[10,11]$.

The paediatric department of the Parakou Teaching Hospital (CHUD B/A) began HIV infection management among children in 2005. The active queue of children exposed and infected with HIV has grown steadily over the years. The authors focused on the survival of HIVinfected children after 5 years of follow-up and the factors associated with this survival.

\section{Materials and Methods}

\section{Type of study, survey period and study population}

This was a descriptive cohort follow-up study, with analytical purposes. The data collection was conducted over a three-month period from April 1 to June 30, 2017. HIV positive children known for at least 5 years (between January 2005 and December 31, 2011) and followed up in the pediatric ward of the CHUD-B/A were registered.

Inclusion criteria: To be included, children were aged at least 5 years on $31^{\text {st }}$ December 2016, with a HIV positive serology after 18 months of age or positive DNA PCR before 18 months of age, not having followed the PMTCT protocol, who were included into the active cohort between 2005 and 2011, whose at least one parent has given free informed consent to participate in the study, whose parents have been residing in Parakou for at least 6 months on the day of the survey; and whose medical file has a good completeness and data quality.

Non-inclusion criteria: Children who have been out of sight for at least 6 months, whose at least one of parents has not given consent to participate in the study, and whose medical records contain incorrect or incomplete data.

Census: This was a comprehensive census of all HIV infected children, followed by the CHDU-B/A pediatric team and meeting our selection criteria.

Data collection: The collection technique used was a review of registers (for child identification), children's medical records, followed by an interview with the children's parents and a thorough clinical examination. A standardized survey sheet was developed for data collection.

Conduct of the survey: As a first step, we discussed a census of all the children involved in our study in the child follow-up register of the CHUD-B/A paediatric ward. In a second step, we met the parents and their children. The collection was made in accordance with the work program agreed with the children's parents. Each child was received with at least one parent by an investigator who explained the objectives of our study. For some deceased children, information was collected from mediators. A mediator is a person living or not with HIV and whose mission is to facilitate the relationship between infected subjects and caregivers. In practice, it is the one who puts himself in the patient's shoes, who reassures him so that he does not feel isolated or stigmatized.

\section{Variables}

Dependent variable: Child survival after 5 years of follow-up was the dependent variable. This variable was a binary qualitative variable with the modalities yes if the child is alive, and No if not.

Independent variables: They were socio-demographic (age at inclusion in the cohort, sex and ethnicity of the child, mother's profession, age of mothers of infected children), related to the health status of children (immunization status, nutritional status, presence or absence of medical complications), related to the follow-up of children infected with HIV: (Age at screening); CD4 count at screening; ART protocols followed, alternative protocol if $A R T$ line replacement, regularity of follow-up, CD4 count and Viral Load (VL) for children living at the time of the survey), those related to death.

\section{Operational definitions}

Follow-up of children: For infected children, WHO recommends at least four (04) consultations per year. In our study, follow-up was considered good when the child had at least 4 consultations per year; average when the child had 3 consultations per year; fair when the child had 2 consultations per year and poor when the child had less than 2 consultations per year.

ARV compliance: In this study, any child who failed 
to take treatment less than 3 times in 3 months was considered to be a good treatment observer. Beyond that, he was considered as unobservant.

Good file completeness: In this work, a file was considered complete and therefore usable when it contains the following information: Socio-demographic information (surname and first name, age, sex, address, mother's occupation, mother's age), particularities at each consultation, a file containing the maximum amount of information on the child's follow-up (date of entry, date of death if deceased, date of withdrawal, ARV prophylaxis, CTM prophylaxis, PCR, CD4, VL).

\section{Data processing and analysis}

At the end of the data collection, the sheets were manually analysed to ensure that the data were complete, consistent in their completion and validated. The data were entered using EPIDATA software version 3.1 en, and were analyzed using STATA software version 11. Proportions were calculated for the qualitative variables. The mean and standard deviation were calculated for quantitative variables with normal distribution, while the median and interquartile interval (Q1; Q3) for quantitative variables with asymmetric distribution.

To synthesize survival probabilities by months of follow-up (duration), we used the survival analysis method. Thus, the event studied was death and the time studied was the duration of follow-up (in months). The Kaplan-Meier method was used to estimate the instantaneous probabilities of survival and the survival trends were compared with the Log-Rank test. Modeling using the Cox regression model was conducted to identify factors associated with death of HIV-infected children. The model was developed using a top-down, step-by-step approach based on $p$-value. Thus, the variables whose $p$-value was $\leq 0.25$ in the bivariate analysis were introduced into the initial model and those in the model with the highest $p$-value were subtracted from the model at each step. The variables used in the final model were those with a $p$-value $<0.05$. Relative risks (RR) were calculated with the Cox model but the determination of their $95 \%$ confidence intervals $(95 \% \mathrm{Cl})$ and $\mathrm{p}$-values were possible using the Wald test. The adequacy of the final model was verified by the proportional risk test.

Ethical considerations: Informed written or oral consent from parents was obtained before the questionnaire was administered. In addition, the parents of the children surveyed were reassured about the anonymity and confidentiality of the information collected. To this end, the use of numeric characters as identification marks on survey forms has been systematically adopted. The permission of the Ethics Committee of the University of Parakou was obtained under number 0013/ CLERB-UP/P/SP/R/SA.
Difficulties and limitations of the study: The main one was the lack of telephone contact in several medical records. This cohort had a varied medical management because, at the beginning of the experiment, ART was conditioned on a CD4 count of less than 200 in these children because these children should first be eligible before being put on ARTs until 2010. HAART was systematically administered to infected children after 2010 independently of CD4 count. Nutritional status assessment of children was done through NCHS charts till 2010. But after that period, we have systematically used WHO 2006 chart standards.

\section{Results}

\section{Description of the sample}

Age at inclusion and sex: The age of the 89 HIVinfected children included in this study was a median of 3 years (interquartile range of $Q 1=2 ; \mathrm{Q} 3=6$ ) with extremes of 0 and 17 years. Children aged 2 to 5 years (51.69\%) were the most represented. For sex, it was predominantly male (56.18\%), with a sex ratio of 1.28 . The Table 1 shows the distribution of HIV-infected children by age and sex.

Residence: Of the 89 respondents, 17 (19.10\%) lived in a rural area and $72(80.90 \%)$ in a urban area.

\section{Current nutritional status and WHO stages}

Nutritional status information was available for 66 infected children. These details are described in Table 1. Of these, 62 (93.94\%) had good nutritional status, 3 $(4.55 \%)$ had moderate acute malnutrition (MAM) and 1 $(1.52 \%)$ had severe acute malnutrition (SAM). For WHO stage, the majority of infected children were at stage 2 (47.19\%).

\section{Complications during follow-up}

Malnutrition was the most common complication during follow-up (see Table 1).

\section{CTM prophylaxis, antiretroviral therapy (ART) and compliance}

A total of $87(97.75 \%)$ children were on Cotrimoxazole (CTM), and $2.25 \%$ were not. 83 (93.26\%) children were on ART and $6.74 \%$ without ARV. Among those on ARVs, $56.63 \%$ were on TDF + 3TC + EFV (Tenofovir, Lamivudine and Efavirenz), $21.69 \%$ on AZT + 3TC + EFV; $8.43 \%$ on $A Z T+3 T C+N V P ; 4.82 \%$ on $A B C+3 T C+L P V / r$ combination; $1.20 \%$ on AZT + 3TC + NVP and $7.23 \%$ on other combinations. Similarly, 62 children $(74.70 \%)$ on ARVs were good observers for this treatment and 21 (25.30\%) were not good observers.

\section{Regularity of follow up}

Of the total number of infected children followed, $85.23 \%$ had good regularity of follow-up. $6.74 \%$ average follow-up, $2.25 \%$ and $5.62 \%$ fair and poor respectively (Table 1). 
Table 1: Distribution of HIV infected children according to socio-demographic characteristics, nutritional status, WHO clinical stages and complications and co-infections.

\begin{tabular}{|c|c|c|}
\hline & Effectif & Percentage (\%) \\
\hline \multicolumn{3}{|l|}{ Age (in years) $(n=89)$} \\
\hline$[0-1]$ & 17 & 19.10 \\
\hline$[1-5]$ & 46 & 51.69 \\
\hline$>5$ & 26 & 29.21 \\
\hline \multicolumn{3}{|l|}{$\operatorname{Sex}(n=89)$} \\
\hline Male & 50 & 56.18 \\
\hline Female & 39 & 43.82 \\
\hline \multicolumn{3}{|c|}{ Nutritional status on admission $(n=66)$} \\
\hline Normal & 62 & 93.94 \\
\hline MAM & 3 & 04.55 \\
\hline SAM & 1 & 01.52 \\
\hline \multicolumn{3}{|l|}{ WHO clinical stages $(n=89)$} \\
\hline Stage 1 & 13 & 14.61 \\
\hline Stage 2 & 42 & 47.19 \\
\hline Stage 3 & 17 & 19.10 \\
\hline Stage 4 & 17 & 19.10 \\
\hline \multicolumn{3}{|l|}{ Complications et Co-morbidities } \\
\hline Malnutrition & 23 & 25.84 \\
\hline Diarrhoea & 21 & 23.60 \\
\hline $\begin{array}{l}\text { Bronchopneumonia (community } \\
\text { acquired) }\end{array}$ & 21 & 23.60 \\
\hline Pulmonary TB & 14 & 15.73 \\
\hline Oral Candidosis & 12 & 13.48 \\
\hline Anemia & 9 & 10.11 \\
\hline Dermatological Complications & 9 & 10.11 \\
\hline ENT Complications & 5 & 05.62 \\
\hline Hepatitis B & 2 & 03.13 \\
\hline Malaria & 2 & 03.13 \\
\hline Depression & 1 & 01.56 \\
\hline Meningitis & 1 & 01.12 \\
\hline Sepsis & 1 & 01.12 \\
\hline Intravascular hemolysis & 1 & 01.56 \\
\hline Psychomotor impairement & 1 & 01.56 \\
\hline
\end{tabular}

\section{CD4 counts}

Table 2 shows the distribution of HIV-infected children by CD4 count at initiation, 1 year, 2, 3, 4 and 5 years of follow up (Table 2).

\section{Estimation of the probability of survival of HIV-} infected children

Of the 89 children infected with HIV, 66 (74.16\%) were alive at the time of the study. The survival function of these children ranged from 0.9663 in the first month to stabilize at 0.74 from 64 months. The probability of survival at 60 months (December 31, 2016) was 0.7637 (Figure 1).

In addition, there was a significant difference $(p$
Table 2: Distribution of HIV infected children according to their immunological status based on CD4 counts or percentage during their follow up and their initial and actual Viral Load (VL).

Number Percentage (\%)

Immunological status at inclusion $(n=89)$

\begin{tabular}{|l|l|l|}
\hline Severe immunodepression & $\mathbf{4 8}$ & $\mathbf{5 3 . 9 3}$ \\
\hline Moderate immunodepression & 14 & 15.73 \\
\hline Mild immunodepression & 10 & 11.24 \\
\hline No immunodepression & 17 & 19.10 \\
\hline
\end{tabular}

Immunological status after 1 year of follow up $(n=83)$

\begin{tabular}{|l|l|l|}
\hline Severe immunodepression & 15 & 18.07 \\
\hline Moderate immunodepression & 16 & 19.28 \\
\hline Mild immunodepression & 11 & 13.25 \\
\hline No immunodepression & $\mathbf{4 1}$ & $\mathbf{4 9 . 4 0}$ \\
\hline
\end{tabular}

Immunological status after 2 years of follow up $(n=76)$

\begin{tabular}{|l|l|l|}
\hline Severe immunodepression & 06 & 07.90 \\
\hline Moderate immunodepression & 10 & 13.16 \\
\hline Mild immunodepression & 07 & 09.21 \\
\hline No immunodepression & $\mathbf{5 3}$ & $\mathbf{6 9 . 7 3}$ \\
\hline
\end{tabular}

Immunological status after 3 years of follow up $(n=72)$

\begin{tabular}{|l|l|l|}
\hline Severe immunodepression & 04 & 5.56 \\
\hline Moderate immunodepression & 08 & 11.11 \\
\hline Mild immunodepression & 10 & 13.89 \\
\hline No immunodepression & $\mathbf{5 0}$ & $\mathbf{6 9 . 4 4}$
\end{tabular}

Immunological status after 4 years of follow up $(n=69)$

\begin{tabular}{|l|l|l|}
\hline Severe immunodepression & 04 & 05.80 \\
\hline Moderate immunodepression & 04 & 05.80 \\
\hline Mild immunodepression & 08 & 11.60 \\
\hline No immunosudepression & $\mathbf{5 3}$ & $\mathbf{7 6 . 8 0}$ \\
\hline
\end{tabular}

Immunological status after 5 years of follow up $(n=68)$

\begin{tabular}{|l|l|l|}
\hline Severe immunodepression & 03 & 04.41 \\
\hline Moderate immunodepression & 03 & 04.41 \\
\hline Mild immunodepression & 06 & 08.82 \\
\hline No immunodepression & $\mathbf{5 6}$ & $\mathbf{8 2 . 3 5}$ \\
\hline
\end{tabular}

Initial viral load (at inclusion) in copy/ $\mu \mathrm{L}(\mathrm{n}=48)$

\begin{tabular}{|l|l|l|}
\hline$<1000$ & $\mathbf{1 8}$ & $\mathbf{3 7 . 5 0}$ \\
\hline $1000-100.000$ & 19 & 35.6 \\
\hline$>100.000$ & 11 & 22.92 \\
\hline
\end{tabular}

Viral load at the time of study in copy/ $\mu \mathrm{L}(\mathrm{n}=25)$

\begin{tabular}{|l|l|l|}
\hline$<1000$ & $\mathbf{2 0}$ & $\mathbf{8 0 . 0 0}$ \\
\hline $1000-100000$ & 02 & 08.00 \\
\hline$>100000$ & 03 & 12.00 \\
\hline
\end{tabular}

$=0.001$ ) between the survival trends according to whether or not the patient was on ARTs (Figure 2).

\section{Factors associated with the death within 5 years of follow up among HIV infected children}

Univariate analysis: The univariate analysis explains the occurrence of death among HIV-infected children in our study by: child occupation, ART initiation, WHO clinical stages, CD4 count at initiation, regularity of 


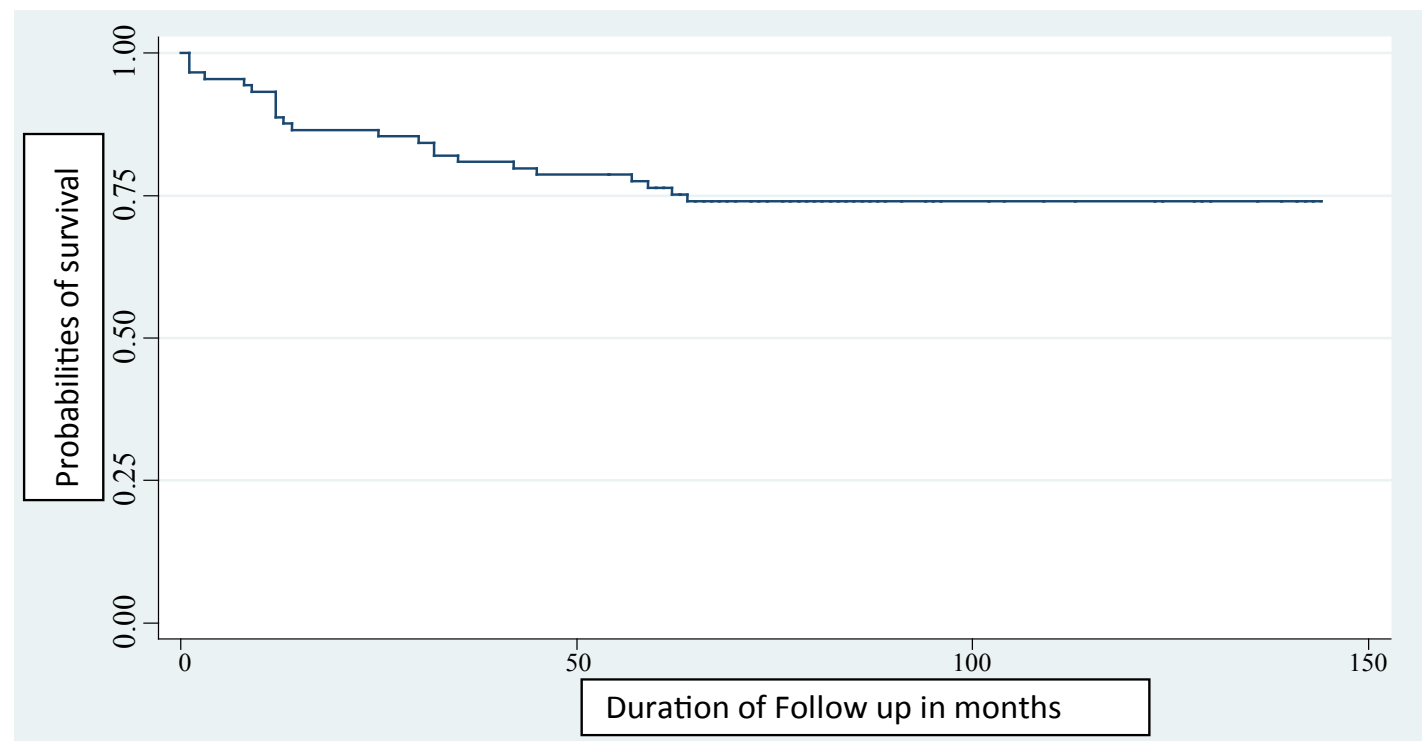

Figure 1: Kaplan-Meier estimation of survival plot of time (in months) to death after ART initiation among HIV infected children.

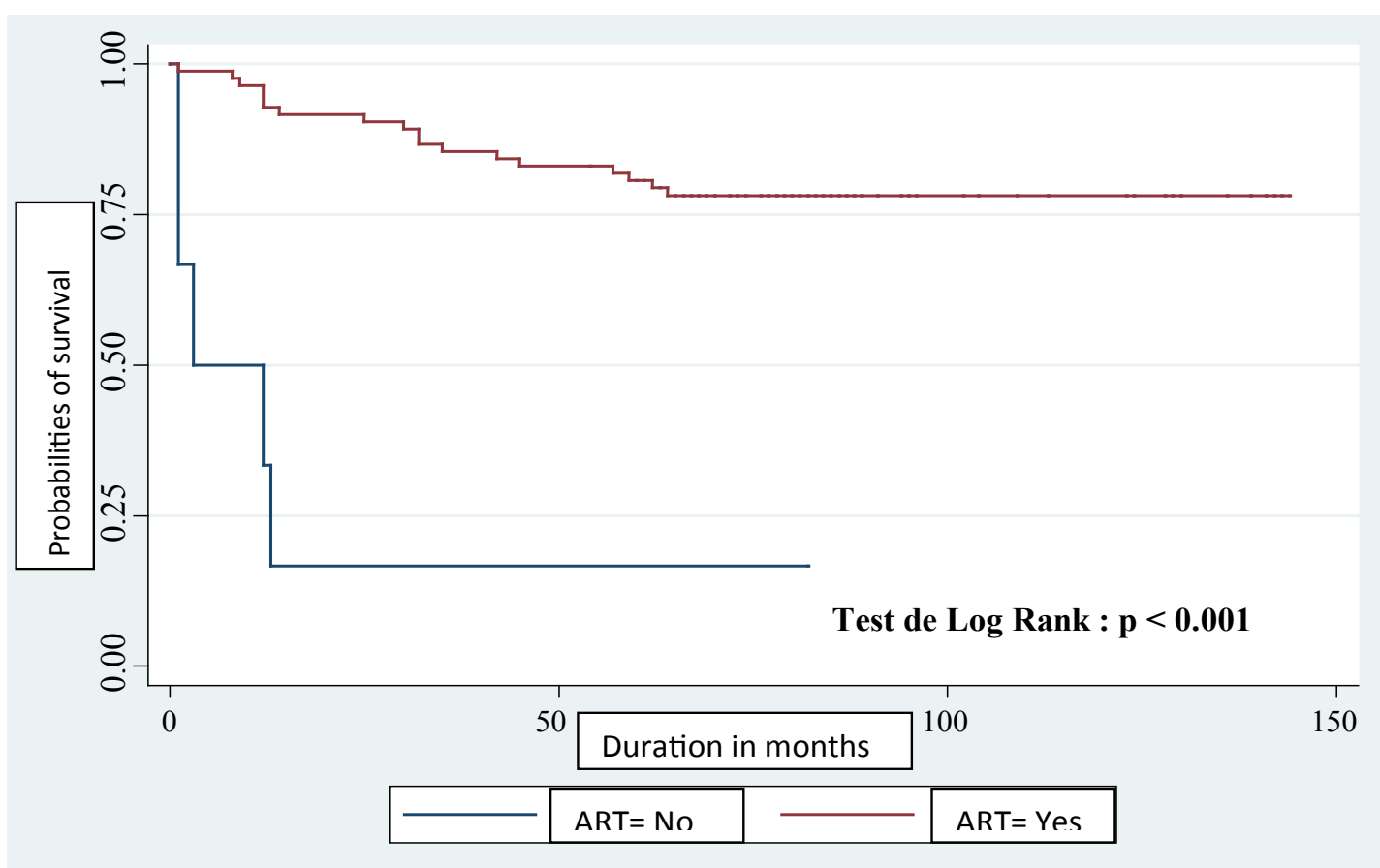

Figure 2: Kaplan-Meier estimation of survival plot of time (follow up in months) to death according to ART among HIV infected. children in Parakou.

follow-up and initial viral load (VL). In addition to this list are complications and co-infections that occurred during follow-up such as: Malnutrition, diarrhea, community acquired bronchopneumonia, and pulmonary tuberculosis.

The table below presents the results of the univariate analysis showing factors associated with the occurrence of death among HIV-infected children followed at CHUD-B/A between 2005-2016 (Table 3).

Multi-variate analysis: After adjustment, four variables were associated with the death of HIV-infected children: Child occupation, WHO clinical stage, regularity of follow-up and child malnutrition (Table 4).
The risk of death was significantly (39 times) higher in children who were at WHO clinical stage $4(p<0.001)$ compared to those at stage 1. HIV-infected children who had poor follow-up were 5.86 times more likely to die $(p=0.007)$ than those who were regularly followed; Infected children who showed malnutrition during follow-up were 4.92 times more likely to die $(p=0.003)$ than others. The risk of death of HIV-infected children was 1.51 times higher among children who weren't going to school $(p=0.039)$ compared to others (Table 5 ).

\section{Discussion}

Validity of the method used and the achievement of objectives 
Table 3: Univariate analysis of factors associated with HIV infected children's death followed at CHUD-B/A between 2005-2016.

\begin{tabular}{|c|c|c|c|c|c|}
\hline & \multicolumn{2}{|l|}{ Death } & \multirow{2}{*}{$\mathbf{R R}_{\mathrm{b}}$} & \multirow{2}{*}{$\mathrm{IC}_{95 \%} \mathrm{RR}$} & \multirow{2}{*}{ p-value } \\
\hline & Yes (\%) & No (\%) & & & \\
\hline \multicolumn{6}{|c|}{ Age (in years at inclusion) } \\
\hline$[0-1]$ & $3(17.65)$ & $14(82.35)$ & 1 & - & \\
\hline$[1-5]$ & $13(28.26)$ & $33(71.74)$ & 1.77 & [0.50-6.23] & 0.370 \\
\hline$>5$ & $7(26.92)$ & $19(73.08)$ & 1.74 & [0.45-6.73] & 0.421 \\
\hline \multicolumn{6}{|l|}{ Sex } \\
\hline Male & $13(26.00)$ & $37(74.00)$ & 1 & - & \\
\hline Female & $10(25.64)$ & $29(74.36)$ & 0.94 & [0.41-2.14] & 0.888 \\
\hline \multicolumn{6}{|c|}{ Area of residency } \\
\hline Rural & $6(35.29)$ & $11(64.71)$ & 1 & - & \\
\hline Urban & $17(23.61)$ & 55 (76.39) & 0.59 & [0.23-1.51] & 0.278 \\
\hline \multicolumn{6}{|c|}{ Children's occupation } \\
\hline Pupils/students & $13(17.33)$ & $62(82.67)$ & 1 & - & \\
\hline Any & $10(71.43)$ & $4(28.57)$ & 1.93 & {$[1.45-2.57]$} & $<0.001$ \\
\hline \multicolumn{6}{|c|}{ Mothers' professions } \\
\hline Civil servants & $3(14.29)$ & $18(85.71)$ & 1 & - & \\
\hline Retailers & $7(29.17)$ & $17(70.83)$ & 2.05 & [0.53-7.94] & 0.297 \\
\hline House-holders & $10(27.78)$ & $26(72.22)$ & 2.00 & [0.55-7.30] & 0.289 \\
\hline Others & $3(37.50)$ & $5(62.50)$ & 2.62 & [0.52-1.01] & 0.237 \\
\hline \multicolumn{6}{|c|}{ WHO clinical stages } \\
\hline Stage 1 & $1(0.69)$ & $12(92.31)$ & 1 & - & \\
\hline Stage 2 & $1(02.38)$ & $41(97.62)$ & 0.31 & [0.01-4.97] & 0.409 \\
\hline Stage 3 & $5(29.41)$ & $12(70.59)$ & 4.23 & [0.49-36.23] & 0.188 \\
\hline Stage 4 & $16(94.12)$ & $1(05.88)$ & 39.38 & [5.01-309.13] & $<0.001$ \\
\hline \multicolumn{6}{|c|}{ Viral load at initation $n=48(\mathrm{in} / \mu \mathrm{L}) \mathrm{p}=1$} \\
\hline$<1000$ & $00(00)$ & $18(100)$ & 1 & - & \\
\hline $1000-100.000$ & $1(05.26)$ & $18(94.40)$ & 0.00 & [undefined] & \\
\hline$>100.000$ & $3(27.27)$ & $8(07.27)$ & 10.90 & [0.0027-2.32] & \\
\hline \multicolumn{6}{|l|}{ ART } \\
\hline Yes & $18(21.69)$ & $65(78.31)$ & 1 & - & \\
\hline No & $5(83.33)$ & $1(16.67)$ & 10.24 & [3.67-28.58] & $<0.001$ \\
\hline \multicolumn{6}{|c|}{ Regularity in the follow up } \\
\hline Good & $15(19.74)$ & $61(80.26)$ & 1 & - & \\
\hline Average & $3(50.00)$ & $3(50.00)$ & 3.19 & [0.92-11.11] & 0.067 \\
\hline Fair & $1(50.00)$ & $1(50.00)$ & 3.14 & [0.41-23.89] & 0.268 \\
\hline Poor & $4(80.00)$ & $1(20.00)$ & 6.36 & [2.08-19.41] & 0.001 \\
\hline \multicolumn{6}{|c|}{ Malnutrition as complication during follow up } \\
\hline No & $12(18.18)$ & $54(81.82)$ & 1 & - & \\
\hline Yes & $11(47.83)$ & $12(52.17)$ & 3.02 & [1.33-6.84] & 0.002 \\
\hline
\end{tabular}

This was a descriptive and analytical cohort follow-up study. It involved a cohort of 89 HIV-infected children. The study allowed us to assess the survival of HIV-infected children followed in the paediatric ward of Parakou Teaching Hospital. It also allowed us to describe the socio-demographic, clinical, immunological, virological, therapeutic and nutritional characteristics of infected children. This first part allowed us to appreciate their survival at 5 years. Using the Kaplan-Meier method, we estimated the probability of survival of infected children at 60 months. Through a univariate and then multivariate analysis, we identified the factors associated with child death.

\section{Validity of the results}

Our study was conducted only at a single site for the care of HIV-infected children in hospitals. The results cannot be generalized to a national health situation. 
Table 4: (Continued and final): Univariate analysis of factors associated death in HIV infected children.

\begin{tabular}{|c|c|c|c|c|c|}
\hline & \multicolumn{2}{|l|}{ Death } & \multirow{2}{*}{$\mathbf{R R}_{\mathrm{b}}$} & \multirow{2}{*}{ IC $_{95 \%}$ RR } & \multirow{2}{*}{ p-value } \\
\hline & Yes (\%) & No (\%) & & & \\
\hline \multicolumn{6}{|c|}{ Diarrhea } \\
\hline No & $11(16.18)$ & $57(83.82)$ & 1 & - & \\
\hline Yes & $12(57.14)$ & $9(42.86)$ & 4.39 & [1.93-10.02] & $<0.001$ \\
\hline \multicolumn{6}{|c|}{ Community acquired bronchopneumonia } \\
\hline No & $22(32.35)$ & $46(67.65)$ & 1 & - & \\
\hline Yes & $1(4.76)$ & $20(95.24)$ & 0.12 & [0.01-0.92] & 0.042 \\
\hline \multicolumn{6}{|c|}{ Pulmonary tuberculosis } \\
\hline No & $14(18.67)$ & $61(81.33)$ & 1 & - & \\
\hline Yes & $9(64.29)$ & $5(35.71)$ & 4.57 & {$[1.97-10.58]$} & $<0.001$ \\
\hline \multicolumn{6}{|c|}{ Candidosis } \\
\hline No & $18(23.38)$ & $59(76.62)$ & 1 & - & \\
\hline Yes & $5(41.67)$ & $7(58.33)$ & 1.99 & [0.73-5.37] & 0.174 \\
\hline \multicolumn{6}{|c|}{ Anemia } \\
\hline No & $21(26.25)$ & 59 (73.75) & 1 & - & \\
\hline Yes & $2(22.22)$ & 7 (77.78) & 0.83 & [0.19-3.54] & 0.803 \\
\hline
\end{tabular}

Table 5: Final multivariate analysis of factors associated with death among HIV infected children.

\begin{tabular}{|c|c|c|c|c|c|}
\hline & \multicolumn{2}{|l|}{ Death } & \multirow{2}{*}{$\mathbf{R R}_{\mathrm{a}}$} & \multirow{2}{*}{ IC $_{95 \%}$ RR } & \multirow{2}{*}{ p-value } \\
\hline & Yes (\%) & No (\%) & & & \\
\hline \multicolumn{6}{|l|}{ Occupation } \\
\hline Pupils/Students & $13(17.33)$ & $62(82.67)$ & 1 & - & \\
\hline Any & $10(71.43)$ & $4(28.57)$ & 1.51 & {$[1.02-2.23]$} & 0.039 \\
\hline \multicolumn{6}{|c|}{ WHO clinical Stage OMS } \\
\hline Stage 1 & $1(07.69)$ & $12(92.31)$ & 1 & - & \\
\hline Stage 2 & $1(02.38)$ & $41(97.62)$ & 0.48 & {$[0.02-8.18]$} & 0.619 \\
\hline Stage 3 & $5(29.41)$ & $12(70.59)$ & 7.03 & {$[0.75-65.54]$} & 0.087 \\
\hline Stage 4 & $16(94.12)$ & $1(05.88)$ & 39.38 & [5.78-429.07] & $<0.001$ \\
\hline \multicolumn{6}{|c|}{ Regularity of follow up } \\
\hline Good & $15(19.74)$ & $61(80.26)$ & 1 & - & \\
\hline Average & $3(50.00)$ & $3(50.00)$ & 1.78 & [0.35-9.06] & 0.484 \\
\hline Fair & $1(50.00)$ & $1(50.00)$ & 2.02 & {$[0.20-19.96]$} & 0.546 \\
\hline Poor & $4(80.00)$ & $1(20.00)$ & 5.86 & [1.61-21.22] & 0.007 \\
\hline \multicolumn{6}{|c|}{ Malnutrition as complication during follow up } \\
\hline No & $12(18.18)$ & $54(81.82)$ & 1 & - & \\
\hline Yes & $11(47.83)$ & $12(52.17)$ & 4.92 & {$[1.69-1.31]$} & 0.003 \\
\hline
\end{tabular}

However, the statistical tests used validated the majority of the results. Sampling was exhaustive for infected children, reducing potential biases in file selection.

Our study included 89 HIV-infected children followed in the paediatric ward of the CHUD-B/A between January 2005 and December 2016. Among the 89 children $56.18 \%$ were male, i.e. a sex ratio of 1.28 . The median age of children at admission was 3 years (36 months) with extremes of 0 and 17 years.

\section{Clinical characteristics}

The majority of infected children were classified as WHO clinical stage 2 (47.19\%). Our results are different from those found by Djadou, et al. in Togo in 2009 which was 35\% for stage 3 versus 33\% for stage 2 [12]. Ouedraogo, et al. in Burkina Faso in 2013, reported that the majority of infected children were classified as Stage 1 [13]. The differences are probably seen in the recruitment strategy of infected children or in the duration of their active cohort. But, it can also be explained through a systematic recruitment of children out of PMTCT program failure.

Complications in infected children in our study were dominated by malnutrition (25.84\%), followed by diarrhoea $(23.60 \%)$, community acquired acute pneumonia (23.60\%), pulmonary tuberculosis (TB) 
(15.65\%) and oral candidiasis (13.48\%). Our results are different from those of the Cher trial in South Africa in 2008, which found a predominance of gastroenteritis (10/30) followed by pneumopathies (3/30) [14]. Reddi, et al. in South Africa in 2007 had identified the same causes with gastroenteritis and tuberculosis predominating [15]. Unlike our study, Djadou, et al. in Togo in 2009 had regained a prevalence of respiratory infections (91\%), followed by Plasmodium falciparum malaria (60\%) and intestinal parasitosis (58\%) [12]. d'Almeida, et al. in Cotonou in 2010 had found candidiasis as first complication [16].

In terms of follow-up, $85.23 \%$ of children had regular follow-up. This rate is higher than that reported by d'Almeida, et al. in Cotonou in 2010, which was 69\% [16].

\section{Immunological and virological characteristics}

At the initiation, nearly half of the children (46.07\%) had a CD4 count of more than 500 cells, $28.09 \%$ had a CD4 count of less than 200 cells. Our results are close to those obtained by Mbaye, et al. in Dakar in 2005 where the average CD 4 count was 483 cells/ $\mu \mathrm{L}$ [17]. An increase in CD4 count or CD4 percentage in under 5 years old children over the years was observed in our study. The same observation has been made by many authors $[14,15,18-22]$. This is an evidence of the effectiveness of ART in the care of infected children.

Data on initial viral load were available in only 48 out of 89 children, $22.92 \%$ of whom had a high VL greater than 100,000 copies. Viral load determination rate is lower than that of Mbaye, et al. in Dakar in 2005, which was $42.85 \%$ (42/98) [17]. This low rate of VL achievement is due to the death of some children before 6 months of ART and to the absence of a PLC (Programmable Logic Controller for VL) for this activity in our centre. So all samples are sent to the national laboratory, which makes VL determination difficult to access in our environment. Sometimes it is the lack of intrants that makes VL realization impossible by the national level that explains this low rate of implementation.

\section{Therapeutic characteristics}

Of the 89 infected children, 97.75\% (87/89) were on Cotrimoxazole. This rate is lower than that obtained by d'Almeida, et al. in Cotonou in 2010, which was (314/317) 99\% [16].

With regard to $A R T$, WHO recommends that all infected children aged 0 to 10 years be systematically treated with ARTs regardless of CD4 level or WHO clinical stage [23]. Of the 89 infected children included, 83 (93.26\%) were on ARTs. This result is higher than that found by d'Almeida, et al. in Cotonou in 2010 (53\%), and that of Mbaye, et al. in Dakar, which was $64.28 \%(36 / 56)$ $[16,17]$. But this rate is close to that reported by Djadou, et al. in Togo in 2009, which was $88.70 \%$ (55/62) [12]. The high rate of children on ART in our study could be explained by the effective implementation of the new WHO recommendations in the paediatric ward of the CHUD-B/A.

Of the 83 children on ART, $56.63 \%$ were on triple therapy made up of one (01) INtTI + 01 INTI + 01 INNTI $(T D F+3 T C+E F V)$. The predominance of this combination in our study is explained on the one hand by the fact that it represents the first-line preferred molecule in children over $15 \mathrm{~kg}$ and on the other hand because it is a fixed combination that is taken only once a day. The variation in treatment regimens is also explained by the evolution of treatment regimens over the years in accordance with WHO recommendations.

In terms of ART compliance, $74.70 \%$ of the children in our study had good ARV compliance compared to $25.30 \%$ non-compliance. This non-compliance rate is higher than that found by Djadou, et al. in Togo in 2009, which was $20 \%$ [12]. Mbaye reported a $75 \%$ compliance rate in Dakar in 2005 [17]. A study conducted in Cameroon in 2007 found a higher compliance rate of $92.81 \%$ [24]. This high rate of non-compliance in our study is explained by the treatment fatigue of some children, especially adolescents, the social vulnerability of some children (orphans, social cases) and the father's lack of involvement in the care of some children. Similarly, children and their parents who have experienced clinical and physical well-being after ART use over time do not perceive the need to continue treatment despite the series of therapeutic education.

\section{Nutritional status of infected children}

The nutritional status at admission of infected children could not be described in our study because of the absence of information on anthropometric parameters of children at admission in some cases, mainly because of the evolution of anthropometric parameters since the introduction of the new WHO growth standards in 2006. We were interested in the current nutritional status of infected children still alive at the time of the study. Of the 66 children still alive, 93.94\% had good nutritional status compared to $4.55 \%$ MAM and $1.52 \%$ MAS. The low rate of SAM in this study could be explained by two reasons: first, by the existence of an effective program for the management of acute malnutrition in the paediatric ward of the CHUD, which allows correct and early detection and management of children, and by the effectiveness of ART, which contributes to improve nutritional status of infected children; in this work, it is the nutritional status after 5 years of ART. The improvement of the nutritional status of infected children undergoing ART and nutritional care had already been highlighted in the work of Agossou, et al. in 2011 [25]. Landes reported that HIV infected women report poorer health status as women with poor BMI and are at high risk of death if they are not under ART [26]. 


\section{Survival of infected children}

Of the 89 infected children included, 66 were still alive on 31 December 2016 , or $74.16 \%$, giving a mortality rate of $25.84 \%$. Survival at 60 months was $76.36 \%$. This rate is similar to the $76.7 \%$ obtained by Collins, et al. in Thailand in 2009 [27]. A study by Jaspan, et al. in South Africa in 2008 estimated a 91\% survival at 24 months and a $90.9 \%$ survival at 36 months $[15,19]$. In this study, we found a significant difference $(p=0.001)$ between the survival curves according to whether or not they were on ARTs or not. This same observation was made by Collins in Thailand in 2009 who found a probability of survival of $94 \%$ at 60 months on ARVs compared to $88 \%$ without ARTs [27]. Mutanga, et al. reported in their work that mortality was highest during the first 3 months of treatment ( $95 \% \mathrm{Cl}: 7.6-16.3)$. In multivariable proportional hazards regression, the adjusted hazards of death were highest among children aged $<1$ year (aHR $=3.1$ (95\% Cl: 1.3-6.4), compared to those aged 6-15 years [28]. It therefore appears that all children in contact with health facilities must be systematically screened for any reason in order to initiate ART early when they are HIV positive. There is also a need to inform and raise public awareness about early care for children infected with HIV.

The univariate analysis allowed us to identify the factors associated with the death of HIV-infected children. In this work, there was no association between sex and death of infected children, unlike Zanoni, et al. who found a significant relationship between sex and death of HIV-infected children $(p=0.03)$ in South Africa in 2009 [11]. Unlike our study, Zanoni, et al. in South Africa in 2009 found a significant association between age and child mortality [11].

We found that the lack of child occupation was associated with child death $(p<0.001)$. This leads to the promotion of schooling for HIV-infected children. In fact, this association could be a confounding factor. However, on reflection, children who are not going to school may be those who are younger and have not yet started school. Thus considered, another explanatory factor could be that younger children are among the one with fast HIV infection evolution with earlier progression to death. But another explanation may be possible in that schooling for these children improves their understanding and make them more prompt to apply recommendations such as regular medication, for example.

\section{WHO clinical stages}

The child's WHO stage 4 status (late WHO stage) at HAART initiation was significantly associated with death $(p<0.001)$. Our results are consistent with those described by several authors and especially of that of Mutanga and al in Zambia [28-31].

\section{CD4 count at inclusion}

Severe immunosuppression (CD4 $<200$ cells $/ \mu \mathrm{L}$ after 5 years of age or low CD4 percentage for under 5 years) at inclusion was significantly associated with HIV-infected children's death in this study. This factor has been identified as a cause of death by many [11,18,29,31-33]. This fact is understandable and expresses in the case of low CD4 levels a severe immunosuppression responsible for the of opportunistic infections occurrence in this context.

\section{Initial viral load (IVL)}

In our study, an initial high IVL greater than 100,000 copies was associated with child death $(p=0.039)$. Our results are similar to those of Eley, et al. in South Africa in 2006 who found that a VL greater than 1000000 copies was independently associated with poor survival [31]. In contrast, Wamalwa, et al. in Kenya in 2007 did not find a link between the initial VL and child survival or death [30]. Nevertheless, it should be noted that very few studies have examined the relationship between initial VL and survival of HIV-infected children.

\section{Absence of ARV treatment}

The absence of ARV treatment in infected children was significantly associated with child death in our study $(p<0.001)$. Our results are comparable to those obtained by Van Kooten Niekerk, et al. in 2006, who found an $87 \%$ reduction in mortality among children on ART compared to children without ART [34].

Type of ART: We found a significant association $(p<$ 0.001 ) between the type of ART and child death. Thus, ART with Nevirapine (NVP) or a protease inhibitor was associated with child death. Our results are similar to those of Violari, et al. in South Africa, which showed that protease inhibitor therapy was associated with poor child survival [14]. But it should be noted that this type of analysis is difficult to prove because there are prescription biases.

ART compliance: Poor ART compliance was significantly associated $(p=0.001)$ with child death. This proves that children and their guardians or tutors must be provided with a good and persitent therapeutic education before treatment is initiated and that regular psychological support must be provided in order to improve compliance.

\section{Regularity of follow-up}

Poor follow-up was associated with children's death ( $p=0.001$ ) in our study. Zanoni, et al. in South Africa in 2011 did not found an association between regular monitoring and HIV-infected children's survival [11] whereas Mutwa, et al. in Rwanda in 2014 found an association between lack of adherence to ART and viral failure of HIV-infected children [35]. However, children with severe immunodepression could have been the 
one with poor compliance to treatment or the one with viral resistance. The last situation cannot be proven in our situation.

\section{Occurrence of complications}

In our study, the occurrence of complications (malnutrition, diarrhea, pulmonary TB and bronchopneumonia) was associated with child deaths. The occurrence of malnutrition during follow-up was significantly associated with death $(p=0.001)$. Our results are similar to those of Collins, et al. in Thailand in 2009, who found a significant association ( $p=0.001$ ) between the occurrence of malnutrition at the beginning of treatment and death [27]. The same association has been identified by several authors $[18,29,34]$. Indeed, there is a link between HIV and malnutrition: HIV affects the nutritional status of infected children, making them more vulnerable to other infections; malnutrition in turn worsens the effects of HIV by further weakening the immune system. Malnutrition and HIV are thus a vicious circle that increases the risk of death.

The onset of diarrhea was also significantly associated $(p<0.001)$ with death in our study. Our results are similar to those of Zanoni, et al. in South Africa in 2011, who found a significant association ( $p=$ 0.008 ) between the occurrence of chronic diarrhea and child mortality [11].

HIV/TB pulmonary co-infection was also associated ( $p<0.001$ ) with the death of the children in our study. Zanoni, et al. in South Africa in 2011 had not found an association between the occurrence of pulmonary TB and child death [11].

The occurrence of pulmonary complications like bronchopneumonia was also associated with death in our study. Wamalwa, et al. in Kenya in 2007 had found pneumonia to be the leading cause of death for children in their study [30].

A multivariate analysis was conducted taking into account variables with complete data for all 89 children included in the study to eliminate confounding factors. After this analysis, four factors were associated with the death of HIV-infected children in our study: Child occupation, WHO stage, regular follow-up and malnutrition. The risk of death was 39 fold increased in children who were at WHO clinical stage $4(p<0.001)$ compared to those in stage 1.

HIV-infected children who had poor follow-up were 5.86 times more likely to die $(p=0.007)$ than those who were regularly well followed; Infected and malnourished children during follow-up were 4.92 times more likely to die ( $p=0.003$ ) than others; The risk of death of HIVinfected children was 1.51 times higher among children who had no occupation ( $p=0.039$ ) compared to others.

These factors, taken individually or together, are worsening factors in the evolution of HIV infection for variables expressing complications and opportunistic infections.

\section{Conclusion}

This work on the 5-year survival of HIV-infected children in the CHUD-B/A paediatric ward, included 89 HIV-infected children. The 5-year survival probability of infected children was 0.7637 . Most children had good regularity of follow-up. The main complications in infected children were malnutrition followed by diarrhea and bronchopneumonia. Factors associated with the death of HIV-infected children were lack of child occupation; clinical stage 4 at inclusion; poor follow-up and the occurrence of malnutrition during follow-up.

\section{Conflict of Interest}

None.

\section{References}

1. WHO (2013) Prevention of mother-to-child transmission of HIVIAIDS in sub-Saharan Africa

2. WHO (2016) Fact sheets: Global HIV statistics. Fact sheet No360.

3. Ouedraogo Yugbaré SO, Zagré N, Koueta F, Dao L, Kam $L$, et al. (2015) Effectiveness of the prevention of motherto-child transmission of the human immunodeficiency virus by the 2010 World Health Organization protocol at the Saint Camille medical centre in Ouagadougou (Burkina Faso). Pan Afr Med J 22: 303.

4. WHO, UNAIDS, UNICEF (2011) Global HIVIAIDS Response. Epidemic update and health sector progress towards universal.

5. Eshleman SH, Mracna M, Guay LA, Deseyve M, Cunningham S, et al. (2001) Selection and fading of resistance mutations in women and infants receiving Névirapine to prevent HIV-1 vertical transmission (HIVNET 012). Aids 15: 1951-1957.

6. Blanche S, Newell ML, Mayaux MJ, Dunn DT, Teglas JP, et al. (1997) Morbidity and mortality in European children vertically infected by HIV-1. The french pediatric HIV infection study group and european collaborative study. $\mathrm{J}$ Acquire Immune Defic Syndr Hum Retrovirol 14: 442-450.

7. Lawson-Evi K, Mouchari-Toure A, Tchama R, Akakpo SA, Atakouma DY, et al. (2010) Devenir des enfants nés de mères séropositives au VIH suivis dans le cadre de la prévention de la transmission de la mère à l'enfant au Togo: Etude portant sur 1042 nourrissons. Bulletin Soc Patho Exot 259-263.

8. Ndondoki Monnykosso E (2012) Research and evaluation of early care strategies for HIV-infected children in West Africa: Access, effectiveness, and determinants. Public health thesis, Université Bordeaux 2 1915: 171.

9. Jacob Adetunji (2000) Trends in under-5 mortality rates and the HIVIAIDS epidemic. Bulletin of the World Health Organization 78: 1200-1206.

10. UNAIDS (2012) Promising practices in community engagement to eliminate new HIV infections in children by 2015 and keep their mothers alive. Case Study 56: 1-56.

11. Zanoni BC, Phungula T, Zanoni HM, France H, Feeney ME (2011) Risk factors associated with increased mortality among HIV infected children initiating antiretroviral therapy (ART) in South Africa. PLoS ONE 6: 1-6. 
12. Djadou KE, Azoumah DR, Saka B, Douti K, Koudaya K, et al. (2012) Monitoring of children infected with HIVIAIDS on antiretroviral treatment in rural. Médecine et Sante 'Tropicales 22: 283-286.

13. Ouedraogo SM, Zoungrana J, Sondo KA, Barro M, Kyelem CG, et al. (2015) Study of the factors associated with therapeutic failure during the follow-up of children infected with HIV1 on Bobo-Dioulasso CHU-Sanou Souro antiretroviral therapy (2007-2013). Mali Medical 30: 26-31.

14. Violari A, Cotton MF, Gibb DM, Babiker AG, Steyn J, et al. (2008) Early antiretroviral therapy and mortality among HIV-infected infants. N Engl J Med 359: 2233-2244.

15. Reddi A, Leeper SC, Grobler AC, Geddes R, France KH, et al. (2007) Preliminary outcomes of a paediatric highly active antiretroviral therapy cohort from KwaZulu-Natal South Africa. BMC Pediatr 7: 13

16. d'Almeida M, Sagbo G, Lalya F, Alao MJ, d'Almeida C, et al. (2013) Profile of HIV-infected children at the National University Hospital of Cotonou (CNHU). Mali Med 28: 2526.

17. Mbaye AD, Signaté Sy $H$, Diagne Guèye NR, Ba A, Sylla A, et al. (2005) Epidemiological and clinical aspects of HIV infection in children at the Albert-Royer National Children's Hospital (Dakar, Senegal). Arch Pediatr 12: 404-409.

18. Bolton-Moore C, Mubiana-Mbewe M, Cantrell RA, Chintu N, Stringer EM, et al. (2007) Clinical outcomes and CD4 cell response in children receiving antiretroviral therapy at primary health care facilities in Zambia. JAMA 298: 18881899.

19. Jaspan HB, Berrisford AE, Boulle AM (2008) Two year outcomes of children on non-nucleoside reverse transcriptase inhibitor and protease inhibitor regimens in a South African pediatric antiretroviral program. Pediatr Infect Dis J 27: 993-998.

20. Van Griensven J, De Naeyer L, Uwera J, Asiimwe A, Gazille C, et al. (2008) Success with antiretroviral treatment for children in Kigali, Rwanda: Experience with health center/ nurse-based care. BMC Pediatr 8: 39.

21. O'Brien DP, Sauvageot D, Zachariah R, Humblet P (2006) In resource-limited settings-limited good early outcomes can be achieved in children using adult-dose combination antiretroviral therapy. AIDS 20: 1955-1960.

22. Wamalwa DC, Farquhar C, Obimbo EM, Selig S, MboriNgacha DA, et al. (2007) Early response to highly active antiretroviral therapy in HIV-1-infected Kenyan children. J Acquir Immune Defic Syndr 45: 311-317.

23. Ministère de la santé du Bénin/PNLS (2016) Politique, normes et procédures pour la prise en charge des personnes vivantes avec le VIH au Bénin, 168.

24. Kissouglenkongo AM, Tietche F, Tene G (2007) Evaluation de l'observance du traitement antirétroviral chez les enfants de 0 à 15 ans infectés par le VIH: Etude menée au Cameroun sur les enfants traités au centre Mère et Enfant de la fondation Chantal Biya à Yaoundé. Sidanet 4 (5): 1001.

25. Agossou J, Adédémy JD, Salifou K (2010) Devenir à 18 mois des enfants nés de mères infectées par le $\mathrm{VIH}$ en milieu hospitalier au Nord du Bénin. Rev Maghr Pédiatr 20: 291-295.

26. Landes $M$, van Lettow $M$, Richard Bedell $R$, Isabell Mayuni I, Adrienne K, et al. (2012) Mortality and health outcomes in HIV-infected and HIV uninfected mothers at 18-20 months postpartum in Zomba District, Malawi. PloS One 7: e44396.

27. Collins JI, Jourdain G, Hansudewechakul R, Kanjanavanit S, Hongsiriwon S, et al. (2010) Long-term survival of HIV-infected children receiving antiretroviral therapy in Thailand: A 5-year observational cohort study. Clin Infect Dis 51: 1449-1457.

28. Mutanga JN, Mutembo S, Ezeamama AE, Xiao Song, Fubisha RC, et al. (2019) Long-term survival outcomes of HIV infected children receiving antiretroviral therapy: An observational study from Zambia (2003-2015). BMC Public Health 19: 115-127.

29. Lumbiganon $P$, Kariminia A, Aurpibul L, Hansudewechakul R, Puthanakit T, et al. (2011) Survival of HIV-infected children: Une étude de cohorte de la région Asie-Pacifique. J Acquir Immune Defic Syndr 2011 ; 56(4) : 365-71.

30. Wamalwa DC, Obimbo EM, Farquhar C, Richardson BA, Mbori-Ngacha DA, et al. (2010) Predictors of mortality in HIV-1 infected children on antiretroviraltherapy in Kenya: A prospective cohort. BMC Pédiatr 10: 33.

31. Eley B, Davies MA, Apolles P, Cowburn C, Buys H, et al. (2006) Antiretroviral treatment for children. S Afr Med J 96: 988-993.

32. Bong CN, Yu JK, Chiang HC, Huang WL, Hsieh TC, et al. (2007) Risk factors for early mortality in children on adult fixed-dose combination antiretroviral treatment in a central hospital in Malawi. AIDS 21: 1805-1810.

33. Kiboneka A, Wangisi J, Nabiryo C, Tembe J, Kusemerererwa $S$, et al. (2008) Clinical and immunological results of the national pediatric cohort receiving a combine antiretroviral therapy in Ouganda. AIDS 22: 2493-2499.

34. Van Kooten Niekerk NK, Knies MM, Howard J, Rabie H, Zeier M, et al. (2006) The first five years of the family clinics for HIV patients at Tygerberg hospital: Family demography, survival of children and cost impact of antiretroviral therapies. J Trop Pediatr 52: 3-11.

35. Mutwa PR, Boer KR, Asiimwe-Kateera B, Tuyishimire D, Muganga N, et al. (2014) Safety and effectiveness of combination antiretroviral therapy during the first year of treatment in hiv-1 infected rwandan children: A prospective study infected Rwandan children: A prospective study. PLoS ONE 9: e111948. 